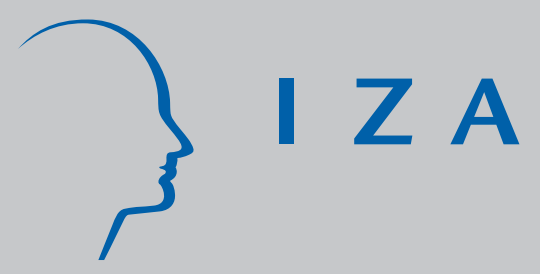

IZA DP No. 3357

Unemployment Benefits and Reservation Wages:

Key Elasticities from a Stripped-Down J ob Search Approach

J ohn T. Addison

Mário Centeno

Pedro Portugal

February 2008 


\title{
Unemployment Benefits and Reservation Wages: Key Elasticities from a Stripped-Down Job Search Approach
}

\author{
John T. Addison \\ Queen's University Belfast, \\ University of South Carolina and IZA \\ Mário Centeno \\ Banco de Portugal \\ and Universidade Técnica de Lisboa \\ Pedro Portugal \\ Banco de Portugal, \\ Universidade NOVA de Lisboa and IZA
}

\author{
Discussion Paper No. 3357 \\ February 2008
}

\author{
IZA \\ P.O. Box 7240 \\ 53072 Bonn \\ Germany \\ Phone: +49-228-3894-0 \\ Fax: +49-228-3894-180 \\ E-mail: iza@iza.org
}

\begin{abstract}
Any opinions expressed here are those of the author(s) and not those of IZA. Research published in this series may include views on policy, but the institute itself takes no institutional policy positions.

The Institute for the Study of Labor (IZA) in Bonn is a local and virtual international research center and a place of communication between science, politics and business. IZA is an independent nonprofit organization supported by Deutsche Post World Net. The center is associated with the University of Bonn and offers a stimulating research environment through its international network, workshops and conferences, data service, project support, research visits and doctoral program. IZA engages in (i) original and internationally competitive research in all fields of labor economics, (ii) development of policy concepts, and (iii) dissemination of research results and concepts to the interested public.
\end{abstract}

IZA Discussion Papers often represent preliminary work and are circulated to encourage discussion. Citation of such a paper should account for its provisional character. A revised version may be available directly from the author. 
IZA Discussion Paper No. 3357

February 2008

\begin{abstract}
Unemployment Benefits and Reservation Wages: Key Elasticities from a Stripped-Down Job Search Approach

This paper exploits survey information on reservation wages and data on actual wages from the European Community Household Panel to deduce in the manner of Lancaster and Chesher (1983) additional parameters of a stylized structural search model; specifically, reservation wage and transition/duration elasticities. The informational requirements of this approach are minimal, thereby facilitating comparisons between countries. Further, its policy content is immediate insofar as the impact of unemployment benefit rules and measures increasing the arrival rate of job offers are concerned. These key elasticities are computed for the United Kingdom and eleven other European nations.
\end{abstract}

JEL Classification: J64, J65

Keywords: reservation wages, probability of reemployment, accepted wages,

unemployment benefits, arrival rate of job offers, wage offer distributions

Corresponding author:

Pedro Portugal

Banco de Portugal

Av. Almirante Reis 71

1150-165 Lisboa

Portugal

E-mail: pportugal@bportugal.pt 


\section{INTRODUCTION}

In this paper we calculate four key elasticities that are centrally related to unemployment duration, using information on asking wages and expected wages from an international data set. Following Lancaster and Chesher's (1983) seminal treatment, these elasticities are derived analytically rather than formally estimated. The four elasticities in question are: (a) the elasticity of the reservation wage with respect to the level of unemployment benefits; (b) the elasticity of reservation wages with respect to the rate of job offers; (c) the probability of reemployment elasticity (or unemployment duration elasticity) with respect to the level of unemployment benefits; and (d) the probability of reemployment elasticity (or unemployment duration elasticity) with respect to the rate of job offers. The data set used is the European Community Household Panel, 1994-99, covering all of the (then) fifteen nations of the European Union (but see below).

Use of Lancaster and Chesher's ingenious approach allows us to make inferences about the behaviour of unemployed job seekers with only minimal information requirements and without the methodological limitations of empirical/regression models. Further, it sidesteps statistical problems associated with the modelling of unobserved individual heterogeneity and true state dependence that are encountered with formal structural models, while yet having a basis in a stylized structural model. Tradeoffs are of course implied by parsimony. That said, there are no such tradeoffs on the data front: the breadth of our sample considerably expands the number of countries for which consistent structural parameters can be provided. The inferences drawn about the behaviour of unemployed job seekers also have clear policy content, most notably with respect to unemployment benefit rules and policies that may increase the arrival rate of job offers by increasing search intensity (e.g. outplacement, active search requirements, and job search assistance).

In what follows, we first set down the barebones of the optimal search model and the specific solutions provided by Lancaster and Chesher. Second, we describe the data set and the final sample of countries. Third, we present the reservation 
wage and duration elasticities, together with a robustness check. Finally, we briefly summarize our findings.

\section{The Stationary Optimal Search Model and Solution Formulae}

Assuming income-maximizing workers, infinite lives, unemployment benefits and jobs (once accepted), sampling without recall, and wage offers that are independent realizations of the random variable $w$ whose distribution function is $F(w)$, the optimal reservation wage - equating the costs and benefits of continued search may be written:

$$
\xi=b+\frac{\lambda}{\rho} \int_{\xi}^{\infty}(w-\xi) d F(w)
$$

where $b$ is the (constant) amount of unemployment benefits net of any search costs, $\rho$ is the discount rate, $w$ is the wage offer, $\lambda$ is the arrival rate of job offers, and $F(w)$ is the cumulative wage offer distribution.

Abstracting from the discount rate (since it disappears from the integrated formulation of the optimality condition) and, for the moment, the mean of the offer distribution, differentiation of equation (1) with respect to $b$ and $\lambda$ will give the responsiveness of the reservation wage to unemployment benefits and the arrival rate of job offers. (As a practical matter, we shall assume that job offers are generated by a Poisson process and, in the discrete time case, arrive with constant probability in each period, ruling out the need for actual information on the arrival rate.) Similarly, differentiating the reemployment probability or hazard rate $\theta=$ $\lambda[1-F(\xi)]$ with respect to $b$ and $\lambda$, will yield the response of the reemployment probability or unemployment duration (since a specification of the hazard function is equivalent to a specification of the distribution of unemployment duration) to unemployment benefits and the arrival rate of job offers.

Lancaster and Chesher note that if we have information on the mean of the distribution of acceptable wage offers, $x[=E(w \mid w \geq \xi)]{ }^{1}$ as well as data for $b$, $\lambda$ (but see above) and $\xi$, we can obtain all the above derivatives. But converting the derivatives into elasticities for the probability of reemployment (with respect 
to benefits and the arrival rate of job offers) requires making some assumption as to the shape of the relevant portion of the wage offer distribution (i.e. exceeding the benefits level), or more precisely the hazard function of the offer distribution at the selected reservation wage, $\frac{f(\xi)}{1-F(\xi)}$. Lancaster and Chesher choose the Pareto distribution allowing them to compute the hazard as $\frac{1}{\sigma \xi}$, where $\sigma$ corresponds to the standard deviation of log wage offers.

The precise solutions obtained by Lancaster and Chesher permitting calculation of each elasticity are given in Table 1. After Lynch (1983), we also provide the solutions assuming an exponential distribution for the relevant portion of the offer distribution.

(Table 1 near here)

\section{THE DATA}

We are aware of only two previous studies using data on $x, b$, and $\xi$ to deduce the structural parameters in Table 1, namely, Lancaster and Chesher (1983) and Lynch (1983) who each use British data. Lancaster and Chesher use data on 642 workers collected in a national survey for Political and Economic Planning in 1974. Lynch uses data from two samples of 70 and 53 unemployed individuals who were actively looking for work in 1980 - from an initial sample of a little under 2,000 young persons in London who were planning to leave school in the summer of 1979.

By contrast, we use information from six waves of the European Community Household Panel (ECHP), 1994-99. The ECHP is a survey based on a standardized questionnaire administered annually to a representative panel of households and individuals. ${ }^{2}$ In 1994, for example, some 60,500 such households or a little over 130,000 adults aged 16 years and above were interviewed. Comparable information is provided for 15 countries. We use data for 12 of the countries: Germany, Denmark, the Netherlands, Belgium, France, the United Kingdom, Ireland, Italy, Greece, Spain, Portugal, and Austria. The three excluded countries are Luxembourg and Sweden where is not possible to follow individuals through time, and Finland where there is no information on monthly unemployment benefits. 
With some exceptions, the data cover the entire period. The main exceptions are Germany and the United Kingdom where we include data from just the 1994-96 waves because of missing data on hourly reservation wages and data on job offers, respectively, in the parent surveys conducted after $1996 .^{3}$

The key pieces of information directly contained in the ECHP that are used in the present inquiry are reservation wages and unemployment benefits. Unlike Lancaster and Chesher we do not have information on expected wages, but as we shall see we can use the ECHP to estimate this magnitude from other information in the dataset.

Beginning with reservation wages, each individual actively looking for a job is asked two questions pertaining first to desired hours of work and second to the minimum income required to work these hours. The actual questions are: 'Assuming you could find suitable work, how many hours per week would you prefer to work in this new job?' and 'What is the minimum net monthly income would you accept to work [number of hours in previous question] hours a week in this new job? ${ }^{4}$

The data on unemployment benefits contained in the ECHP is with one exception a monthly measure. It is comparable to the Lancaster-Chesher measure of unemployment income but, as is the case for all our variables, is provided in continuous rather than categorical form.

Although the ECHP does not contain information on expected wages, we were nevertheless able to compute an expected wage for each unemployed worker using the empirical distribution of wages of the contemporaneously employed population who had found a job in the survey year. Specifically, at survey date we matched each unemployed individual with his/her counterpart in the recently employed population. The matching was on the basis of two gender, five age, and three education categories. ${ }^{5}$

Each unemployed individual was therefore assigned to one of 30 cells and attributed the average monthly earnings of that cell, subject to the latter being at least equal to the matched unemployed individual's reservation wage. Our device 
of using information on current starting wages to proxy the wage offer distribution faced by the currently unemployed may be superior to the construct used by Lancaster and Chesher. This is because it is based on convincing information on the relevant wage offer distribution and is computed in a way that corresponds precisely to the theorectical notion of conditional (on reservation wages) expected wages.

Figure 1 provides the resulting density functions of expected wages for each country. Also included in the figure are the corresponding unemployment benefits and reservation wage densities. The expected wage distribution is, by construction, displaced to the right of the reservation wage distribution. ${ }^{6}$

(Figure 1 near here)

As a check, we shall also provide results for a sample in which the expected wage is derived on the basis of the unemployed individual's subsequent reemployment wage (i.e. at following survey wave). Defining expected wages in this manner could be an attractive alternative in a rational expectations sense. The problem is that the sample is much reduced because only a minority of those workers unemployed at finds work. Moreover, imposition of the restriction that accepted wages exceed not only unemployment benefits but, more importantly, the reservation wage resulted in a further large reduction - of around 40 percent - in sample size.

Before presenting our findings, we need to address the quality of our data and their adequacy for an analysis of reservation wages in particular. Principally, although past studies suffer from a potential problem of low response rates to the reservation wage question, this is not a consideration with the present dataset since response rates exceed 90 percent. Further, the restriction that reservation wages exceed unemployment benefits is also generally met in the data (see Addison et al., 2004).

\section{FINDINGS}

The procedure of Lancaster and Chesher generates elasticity values for each individual in the sample. Misreporting, measurement error, and division by numbers 
close to zero may result in some aberrant elastiticies (or outliers) which may corrupt the computation of sample means. In order to avoid the undesirable contamination from extreme values, we computed median elasticities. ${ }^{7}$

The computed median elasticities and the corresponding bootstrap standard deviations are contained in Table 2. Panel (a) of the table gives results for the unrestricted sample, while panel (b) imposes the theoretical restriction of the stationary model that the reservation wage should exceed the benefit level. As can be seen, the restriction results in some loss of observations (most especially for the Netherlands) but the results are broadly comparable as between panels, with greater variability for the transition elasticities with respect to unemployment benefits in panel (b). In what follows we will focus on the restricted sample, while entering the caveat that the theoretical restriction may not necessarily be always appropriate; for example, where benefits are finite, the reservation wage may indeed fall below the benefit level.

(Table 2 near here)

It is apparent that the reservation wage elasticities are comparatively small, falling within the range 0.107 to 0.427 for the benefit elasticity of reservation wages and 0.109 to 0.260 in the case of the offer probability elasticity of reservation wages. For their part, the transition elasticities can be large. As a case in point, assuming a Pareto (Exponential) distribution for the relevant portion of the wage offer distribution, a 10 per cent increase in benefit levels is associated with a 18.4 (14.3) per cent fall in escape rates for Denmark where the highest disincentive effects are observed. For the Pareto tail, three out of twelve transition elasticities exceed unity. As far as the effect of job offers on transition probabilities is concerned, however, the elasticities are more closely clustered across nations and more so in the case of the Exponential than the Pareto distribution. Observe that the net effect of an increase in the probability of an offer on escape rates is always positive, meaning that the effect on asking wages is dominated by the effects of more offers. Note, finally, that the elasticities are estimated with considerable precision. $^{8}$ 
(Table 3 near here)

It is interesting to compare in Table 3 our findings for the United Kingdom with those obtained by Lancaster and Chesher $(1983$, pp. 1668, 1671) for all workers and also by Lynch (1983, p. 277) for school leavers. Note that in order to effect these comparisons we are here using mean rather than median elasticities. A full set of mean elasticities corresponding to those given in Table 2 is provided in Appendix Table 1. Given the differences in years and samples, the range within which the estimates fall is fairly narrow, but only for the effect of benefits on transition probabilities is there close correspondence between our results and those of Lancaster and Chesher (Pareto distribution) and Lynch (Exponential distribution). As far as the results for other countries are concerned, there are few points of comparison as most studies pertain to the United States where estimates of the four elasticities lie below those reported in the table (a summary of these studies is provided in Devine and Kiefer, 1991). But evidence on the elasticity of the reservation wage with respect to benefits provided by Ridder and Gorter (1986) in a structural model for the Netherlands (0.450) closely resembles the corresponding estimate for that country in Appendix Table 1 (0.464). ${ }^{9}$

(Table 4 near here)

In Table 4 we calculate a set of elasticities that parallel those reported in Table 2 but this time using information on the same individual over sequential surveys. That is, we consider individuals who are unemployed at time $t$ but employed at time $t+1$. The estimate of the unemployed individual's expected wage is now his/her accepted wage, subject to the reemployment wage not only exceeding the benefit level but also the stated reservation wage. Necessarily, the sample is much reduced because only a minority of unemployed individuals go on to report a wage at $t+1$ - the majority remain unemployed and yet others become inactive. But the results in Table 4 do not produce any shocks in the form of perverse elasticities. In this sense our main findings pass a crude robustness check. Nevertheless, although estimates of the two reservation wage elasticities again conform to a fairly narrow band, they are generally lower than before. The transition elasticities with respect 
to the arrival rate of job offers also fall within a fairly narrow range and are again somewhat smaller (under both assumptions as to the tail of the distribution) than before. Major differences do, however, characterize the transition elasticities with respect to unemployment benefits. As is evident, the absolute values reported for each distribution now almost always exceed the previous values.

\section{Conclusions}

In an ingenious paper, Lancaster and Chesher (1983) used survey data on unemployed persons in the United Kingdom and economic theory to deduce (rather than estimate via a formal statistical model) the structural parameters of the stationary optimal search model. We have followed their methodology - although our treatment differs from theirs in the manner of the derivation of the mean of the distribution of acceptable wage offers - to obtain updated estimates of reservation wage and transition elasticities for the United Kingdom and for eleven other European nations as well. Our findings, which are numerically consistent with the theory, are found to be robust with respect to an alternative definition of the expected wage and hence configuration of the data. Moreover, our preferred estimates closely accord with those provided by Lancaster and Chesher using U.K. data for 1984 .

We are unaware of any other consistently estimated cross-country findings. Given the policy content of the elasticities with respect to unemployment, and subject to further corroboration of at least some of the individual country findings, suggestive lines of future inquiry might include investigating whether variation in the 'indicative' estimates is associated with the generosity of a country's unemployment benefit system or with the stringency of its employment protection regime.

\section{ACKNOWLEDGMENTS}

We are indebted to two anonymous referees for their helpful comments. Partial financial support from the Fundação para a Ciência e a Tecnologia is also gratefully acknowledged. The usual disclaimers apply. 


\section{Notes}

${ }^{1}$ Lancaster and Chesher (1983) interpret answers to the question 'How much take-home pay would you expect to earn in a new job?'as revealing this magnitude.

${ }^{2}$ The actual data cover the interval January 1993 through December 1998 as the questions in each survey pertaining to labour market experience relate to the preceding calendar year. The ECHP covers a very wide range of topics apart from the individual's economic activity and income, including health, education, housing, pensions and insurance, and social relations (see, for example, EUROSTAT, 1999).

${ }^{3}$ Information on the reservation wage is unavailable for the Netherlands in 1994 and 1995.

${ }^{4}$ This reservation wage variable was duly deflated by the relevant national consumer price index, as were all nominal arguments.

${ }^{5}$ The schooling categories identify basic, secondary, and tertiary education. The five age groups correspond to the following intervals: $17-25$ years; $26-35$ years; $36-45$ years; $46-55$ years; and $56-65$ years.

${ }^{6}$ Because the unemployment benefits are highly concentrated for Ireland and the U.K. we introduce a second vertical scale in the graphs of the densities for these two countries

${ }^{7}$ Simple sample averages are provided in Appendix Tables 1 and 2

${ }^{8}$ The bootstrap standard deviations were obtained from 200 replications. Using the more conventional standard error of the mean formulae, gives identical results.

${ }^{9}$ However, other results for the Netherlands (cited in Cahuc and Zylberberg, 2004, p. 157) are less conformable. 


\section{References}

Addison, John T., Mário Centeno, and Pedro Portugal (2004).

Reservation Wages, Search Duration, and Accepted Wages in Europe. IZA

Discussion Paper No. 1252. Bonn: Institute for the Study of Labor/IZA.

Cahuc, Pierre, And André Zylberberg, A. (2004). Labor Economics. Cambridge, MA: MIT Press.

Devine, Theresa J., And Nicholas M. Kiefer (1991). Empirical Labor Economics - The Search Approach. New York and Oxford: Oxford University Press.

EUROSTAT, (1999). European Community Household Panel. Longitudinal Users' Database. Waves 1, 2 and 3. Manual. Luxembourg: EUROSTAT.

Lancaster, Tony, And Andrew Chesher (1983). An Econometric Analysis of Reservation Wages. Econometrica 51 (6): 1661-1676.

Lynch, Lisa M. (1983). Job Search and Youth Unemployment. Oxford Economic Papers 35 (November): 271-282

Ridder, G., And K. Gorter (1986). Unemployment Benefits and Search Behavior: An Empirical Investigation. Unpublished Paper, University of Groningen. 
Table 1: The Elasticity Measures and Their Solution

\begin{tabular}{lcc}
\hline Elasticity & Notation & Solution \\
\hline Reservation Wage w.r.t. the Benefit Level & $\eta_{\xi, b}$ & $\frac{b x-\xi}{\xi x-b}$ \\
Reservation Wage w.r.t. the Rate of Job Offers & $\eta_{\xi, \lambda}$ & $\frac{\xi-b}{\xi} \frac{x-\xi}{x-b}$ \\
Reemployment Probability w.r.t. the Benefit Level, Pareto Assumption & $\eta_{\theta, b}$ & $-\frac{b}{\sigma \xi} \frac{x-\xi}{x-b}$ \\
Reemployment Probability w.r.t. the Benefit Level, Exponential Assumption & $\eta_{\theta, b}$ & $-\frac{b}{x-b}$ \\
Reemployment Probability w.r.t the Rate of Job Offers, Pareto Assumption & $\eta_{\theta, \lambda}$ & $1-\frac{\xi-b}{\sigma \xi} \frac{x-\xi}{x-b}$ \\
Reemployment Probability w.r.t the Rate of Job Offers, Exponential Assumption & $\eta_{\theta, \lambda}$ & $1-\frac{\xi-b}{x-b}$ \\
\hline
\end{tabular}

Note: The parameter $\sigma$ is obtained from $\sigma=\frac{x-\xi}{x}$. 
Table 2

MEDIAN BENEFIT AND OFFER PROBABILITY ELASTICITIES OF RESERVATION WAGES AND UNEMPLOYMENT DURATION BY COUNTRY 1993-98

\begin{tabular}{|c|c|c|c|c|c|c|c|c|c|c|c|c|}
\hline Country/Elasticity & Germany & Denmark & Netherlands & Belgium & France & U.K. & Ireland & Italy & Greece & Spain & Portugal & Austria \\
\hline \multicolumn{13}{|c|}{ (a) No sample restrictions } \\
\hline \multirow{2}{*}{ 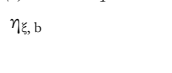 } & 0.271 & 0.416 & 0.618 & 0.166 & 0.247 & 0.194 & 0.199 & 0.133 & 0.109 & 0.333 & 0.317 & 0.30 \\
\hline & $(0.010)$ & $(0.014)$ & $(0.079)$ & $(0.010)$ & $(0.007)$ & $(0.017)$ & $(0.020)$ & $(0.016)$ & $(0.007)$ & $(0.013)$ & $(0.013)$ & $(0.024$ \\
\hline \multirow[t]{2}{*}{$\eta_{\xi, \lambda}$} & 0.168 & 0.094 & 0.097 & 0.130 & 0.180 & 0.225 & 0.188 & 0.114 & 0.156 & 0.128 & 0.127 & 0.14 \\
\hline & $(0.004)$ & $(0.003)$ & $(0.019)$ & $(0.005)$ & $(0.003)$ & $(0.010)$ & $(0.008)$ & $(0.005)$ & $(0.009)$ & $(0.002)$ & $(0.005)$ & $(0.006$ \\
\hline \multicolumn{13}{|l|}{ Pareto distribution } \\
\hline \multirow[t]{2}{*}{$\eta_{\theta, \mathrm{b}}$} & -0.994 & -2.000 & -1.602 & -835.000 & -0.868 & -0.531 & -0.838 & -0.925 & -0.645 & -1.455 & -1.448 & -1.27 \\
\hline & $(0.023)$ & $(0.065)$ & $(0.111)$ & $(0.048)$ & $(0.022)$ & $(0.034)$ & $(0.038)$ & $(0.078)$ & $(0.017)$ & $(0.035)$ & $(0.047)$ & $(0.070$ \\
\hline \multirow[t]{2}{*}{$\eta_{\theta, \lambda}$} & 0.278 & 0.416 & 0.619 & 0.174 & 0.248 & 0.195 & 0.203 & 0.141 & 0.111 & 0.338 & 0.326 & $0.30-$ \\
\hline & $(0.010)$ & $(0.014)$ & $(0.068)$ & $(0.009)$ & $(0.007)$ & $(0.017)$ & $(0.020)$ & $(0.020)$ & $(0.008)$ & $(0.012)$ & $(0.013)$ & $(0.027)$ \\
\hline \multicolumn{13}{|c|}{ Exponential distribution } \\
\hline \multirow{2}{*}{$\eta_{\theta, \mathrm{b}}$} & -0.670 & -1.500 & -0.864 & -0.579 & -0.580 & -0.284 & -0.600 & -0.715 & -0.504 & -1.063 & -1.089 & -0.911 \\
\hline & $(0.016)$ & $(0.055)$ & $(0.074)$ & $(0.026)$ & $(0.012)$ & $(0.007)$ & $(0.030)$ & $(0.079)$ & $(0.023)$ & $(0.029)$ & $(0.045)$ & $(0.046)$ \\
\hline \multirow[t]{2}{*}{$\eta_{\theta, \lambda}$} & 0.492 & 0.541 & 0.777 & 0.349 & 0.493 & 0.534 & 0.439 & 0.291 & 0.277 & 0.511 & 0.480 & 0.50 \\
\hline & $(0.014)$ & $(0.014)$ & $(0.038)$ & $(0.015)$ & $(0.007)$ & $(0.024)$ & $(0.027)$ & $(0.022)$ & $(0.014)$ & $(0.013)$ & $(0.017)$ & $(0.032)$ \\
\hline $\mathrm{n}$ & 941 & 659 & 156 & 684 & 1675 & 398 & 260 & 193 & 283 & 1055 & 420 & 177 \\
\hline \multicolumn{13}{|c|}{ (b) Restriction: reservation wage $>$ unemployment benefits } \\
\hline \multirow[t]{2}{*}{$n_{\xi, \mathrm{b}}$} & 0.250 & 0.328 & 0.427 & 0.163 & 0.231 & 0.150 & 0.189 & 0.157 & 0.107 & 0.298 & 0.390 & 0.27 \\
\hline & $(0.010)$ & $(0.013)$ & $(0.041)$ & $(0.011)$ & $(0.005)$ & $(0.010)$ & $(0.015)$ & $(0.022)$ & $(0.006)$ & $(0.009)$ & $(0.014)$ & $(0.020$ \\
\hline \multirow[t]{2}{*}{$\eta_{\xi, \lambda}$} & 0.180 & 0.109 & 0.172 & 0.141 & 0.188 & 0.260 & 0.192 & 0.117 & 0.156 & 0.138 & 0.135 & 0.15 \\
\hline & $(0.003)$ & $(0.002)$ & $(0.014)$ & $(0.005)$ & $(0.003)$ & $(0.009)$ & $(0.008)$ & $(0.005)$ & $(0.009)$ & $(0.002)$ & $(0.004)$ & 0.005 \\
\hline \multicolumn{13}{|l|}{ Pareto distribution } \\
\hline \multirow[t]{2}{*}{$\eta_{\theta, \mathrm{b}}$} & -0.961 & -1.839 & -1.258 & -0.787 & -0.824 & -0.426 & -0.826 & -0.993 & -0.645 & -1.355 & -1.426 & -1.20 \\
\hline & $(0.027)$ & $(0.072)$ & (0.127) & $(0.043)$ & $(0.018)$ & $(0.016)$ & $(0.044)$ & $(0.071)$ & $(0.017)$ & (0.036) & (0.044) & $(0.059$ \\
\hline \multirow[t]{2}{*}{$\eta_{\theta, \lambda}$} & 0.255 & 0.333 & 0.431 & 0.165 & 0.233 & 0.151 & 0.189 & 0.161 & 0.111 & 0.300 & 0.313 & 0.27 \\
\hline & $(0.008)$ & $(0.015)$ & $(0.044)$ & $(0.008)$ & $(0.006)$ & $(0.009)$ & $(0.019)$ & $(0.019)$ & $(0.007)$ & $(0.009)$ & $(0.013)$ & $(0.021)$ \\
\hline \multicolumn{13}{|c|}{ Exponential distribution } \\
\hline \multirow[t]{2}{*}{$\eta_{\theta, \mathrm{b}}$} & -0.645 & -1.429 & -0.721 & -0.559 & -0.561 & -0.266 & -0.577 & -0.788 & -0.509 & -0.995 & -1.066 & -0.86 \\
\hline & $(0.014)$ & $(0.047)$ & $(0.042)$ & $(0.025)$ & $(0.011)$ & $(0.006)$ & $(0.027)$ & $(0.073)$ & $(0.025)$ & $(0.028)$ & $(0.040)$ & $(0.044$ \\
\hline \multirow[t]{2}{*}{$\eta_{\theta, 2}$} & 0.465 & 0.473 & 0.682 & 0.341 & 0.473 & 0.464 & 0.417 & 0.316 & 0.276 & 0.474 & 0.474 & 0.45 \\
\hline & $(0.009)$ & $(0.016)$ & $(0.034)$ & $(0.015)$ & $(0.008)$ & $(0.015)$ & $(0.027)$ & $(0.016)$ & $(0.014)$ & $(0.008)$ & $(0.016)$ & $(0.034$ \\
\hline $\mathrm{n}$ & 835 & 590 & 107 & 630 & 1531 & 319 & 250 & 161 & 279 & 942 & 392 & 15 \\
\hline
\end{tabular}

Source

European Community Household Panel, 1994-99

Bootstrap standard deviations in parenthesis 
Table 3: A Comparison of Results for the United Kingdom

\begin{tabular}{lccc}
\hline & Lancaster and Chesher & Lynch & ECHP \\
\hline$\eta_{\xi, b}$ & 0.135 & 0.106 & 0.237 \\
$\eta_{\xi, \lambda}$ (Pareto) & 0.107 & 0.146 & 0.251 \\
$\eta_{\theta, b}$ (Exponential) & -1.030 & -0.483 & -0.873 \\
$\eta_{\theta, b}$ (Pareto) & - & -0.559 & -0.502 \\
$\eta_{\theta, \lambda}$ (Panonential) & 0.190 & 0.298 & 0.399 \\
$\eta_{\theta, \lambda}$ (Expon & - & 0.252 & 0.496 \\
\hline
\end{tabular}


Table 4

MEDIAN BENEFIT AND OFFER PROBABILITY ELASTICITIES OF RESERVATION WAGES AND UNEMPLOYMENT DURATION BY COUNTRY, USING ACTUAL ACCEPTED WAGES, $1993-98$

\begin{tabular}{|c|c|c|c|c|c|c|c|c|c|c|c|c|}
\hline Country/Elasticity & Germany & Denmark & Netherlands & Belgium & France & U.K. & Ireland & Italy & Greece & Spain & Portugal & Austria \\
\hline \multicolumn{13}{|c|}{ Restriction: reservation wage $>$ unemployment benefits and reservation wages < accepted wages } \\
\hline \multirow[t]{2}{*}{$\eta_{\xi, \mathrm{b}}$} & 0.179 & 0.327 & 0.213 & 0.091 & 0.156 & 0.212 & 0.160 & 0.100 & 0.148 & 0.284 & 0.237 & 0.327 \\
\hline & $(0.021)$ & $(0.030)$ & $(0.091)$ & $(0.020)$ & $(0.022)$ & $(0.036)$ & $(0.035)$ & $(0.028)$ & $(0.026)$ & $(0.029)$ & $(0.047)$ & $(0.035)$ \\
\hline \multirow[t]{2}{*}{$\eta_{\xi, \lambda}$} & 0.089 & 0.066 & 0.046 & 0.066 & 0.068 & 0.106 & 0.125 & 0.079 & 0.200 & 0.059 & 0.041 & 0.072 \\
\hline & $(0.008)$ & $(0.005)$ & $(0.018)$ & $(0.010)$ & $(0.009)$ & $(0.024)$ & $(0.018)$ & $(0.015)$ & $(0.019)$ & $(0.007)$ & $(0.013)$ & $(0.013)$ \\
\hline \multicolumn{13}{|l|}{ Pareto distribution } \\
\hline \multirow[t]{2}{*}{$\eta_{\theta, \mathrm{b}}$} & -1.321 & -2.636 & -1.614 & -0.991 & -1.225 & -0.617 & -1.042 & -1.067 & -0.750 & -1.912 & -2.190 & -2.027 \\
\hline & $(0.092)$ & $(0.214)$ & $(0.427)$ & $(0.168)$ & $(0.277)$ & $(0.044)$ & $(0.166)$ & $(0.156)$ & $(0.027)$ & $(0.126)$ & $(0.275)$ & $(0.209)$ \\
\hline \multirow[t]{2}{*}{$\eta_{\theta, \lambda}$} & 0.201 & 0.393 & 0.331 & 0.135 & 0.207 & 0.212 & 0.166 & 0.147 & 0.158 & 0.375 & 0.318 & 0.346 \\
\hline & $(0.016)$ & $(0.032)$ & $(0.091)$ & $(0.013)$ & $(0.021)$ & $(0.038)$ & $(0.037)$ & $(0.017)$ & $(0.001)$ & $(0.028)$ & $(0.036)$ & $(0.032)$ \\
\hline \multicolumn{13}{|c|}{ Exponential distribution } \\
\hline \multirow[t]{2}{*}{$\eta_{\theta, \mathrm{b}}$} & -1.143 & -2.214 & -0.945 & -0.775 & -1.062 & -0.380 & -0.795 & -0.565 & -0.556 & -1.600 & -1.689 & -1.500 \\
\hline & $(0.075)$ & $(0.166)$ & $(0.216)$ & $(0.110)$ & $(0.254)$ & $(0.024)$ & $(0.143)$ & $(0.132)$ & $(0.053)$ & $(0.098)$ & $(0.248)$ & $(0.184)$ \\
\hline \multirow[t]{2}{*}{$\eta_{\theta, \lambda}$} & 0.278 & 0.429 & 0.316 & 0.218 & 0.303 & 0.515 & 0.342 & 0.200 & 0.364 & 0.455 & 0.374 & 0.510 \\
\hline & $(0.023)$ & $(0.033)$ & $(0.100)$ & $(0.031)$ & $(0.030)$ & $(0.044)$ & $(0.047)$ & $(0.021)$ & $(0.044)$ & $(0.026)$ & $(0.045)$ & $(0.061)$ \\
\hline $\mathrm{n}$ & 129 & 115 & 24 & 60 & 120 & 59 & 45 & 27 & 32 & 153 & 50 & 25 \\
\hline
\end{tabular}

Source

European Community Household Panel, 1994-s

Note

Bootstrap standard deviations in parenthesis 

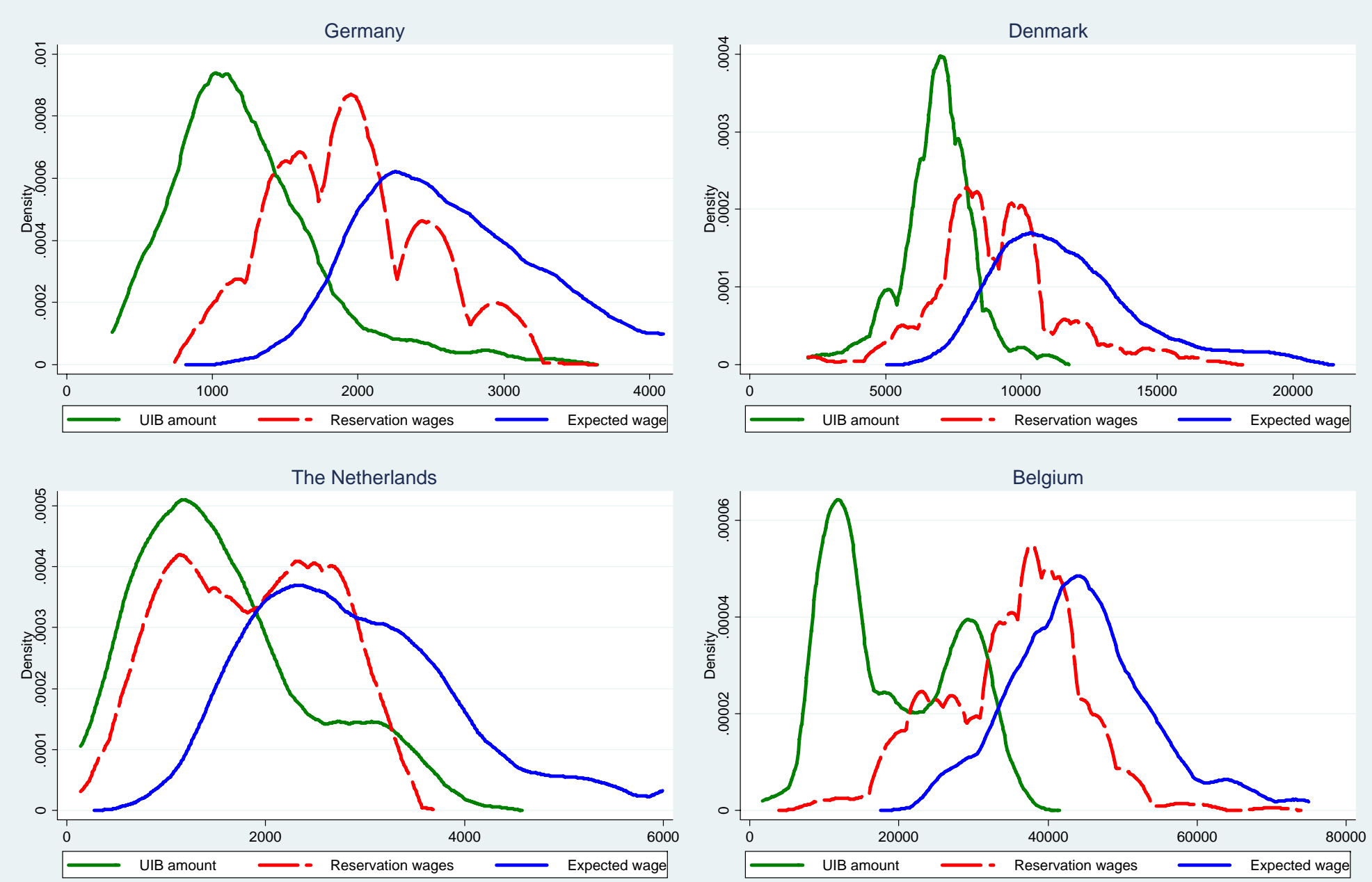

Source: European Community Household Panel, 1994-1999 Figure1: Unemployment benefits, reservation wages and expected wages 

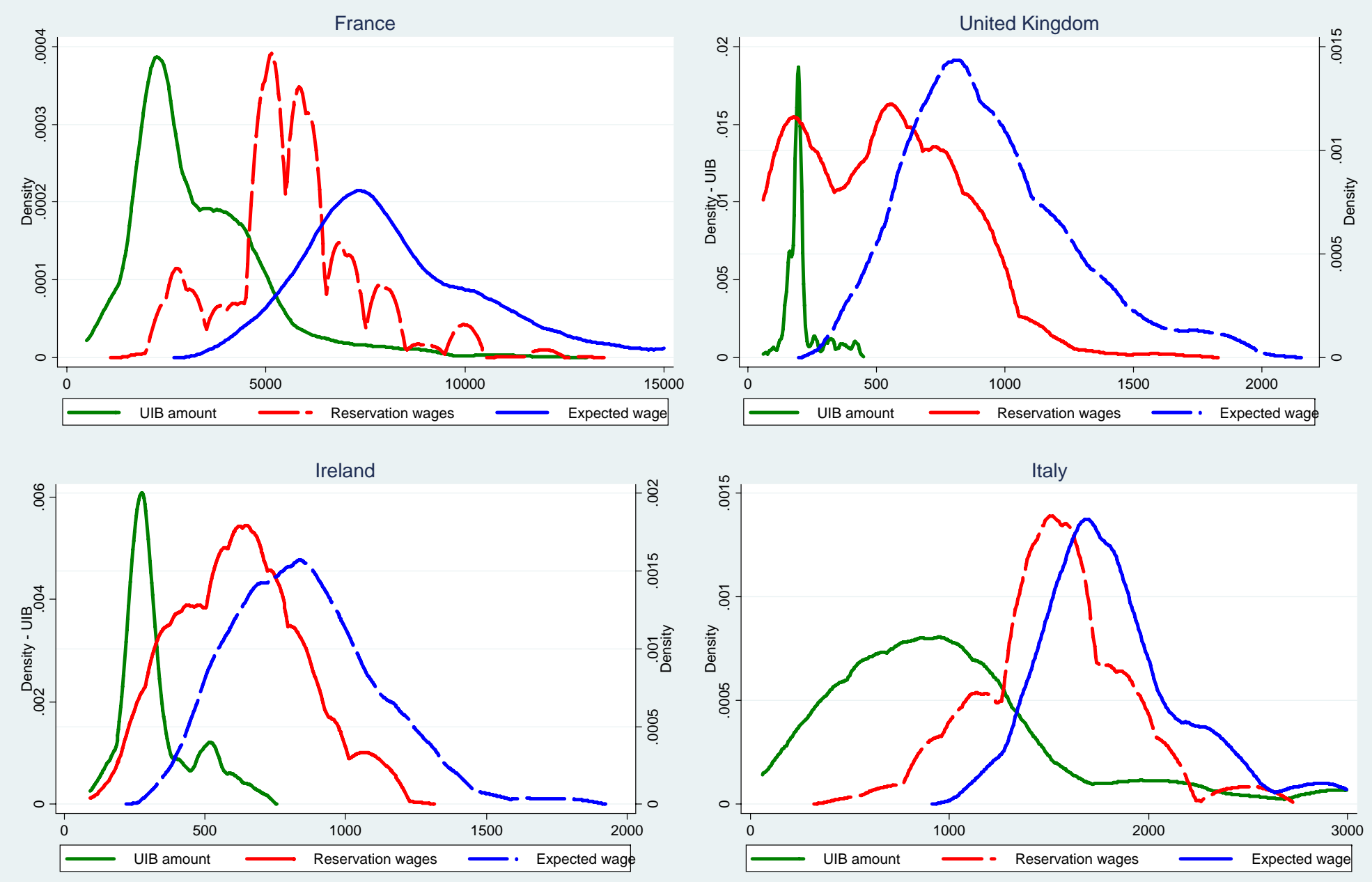

Source: European Community Household Panel, 1994-1999

Figure1(continued): Unemployment benefits, reservation wages and expected wages 

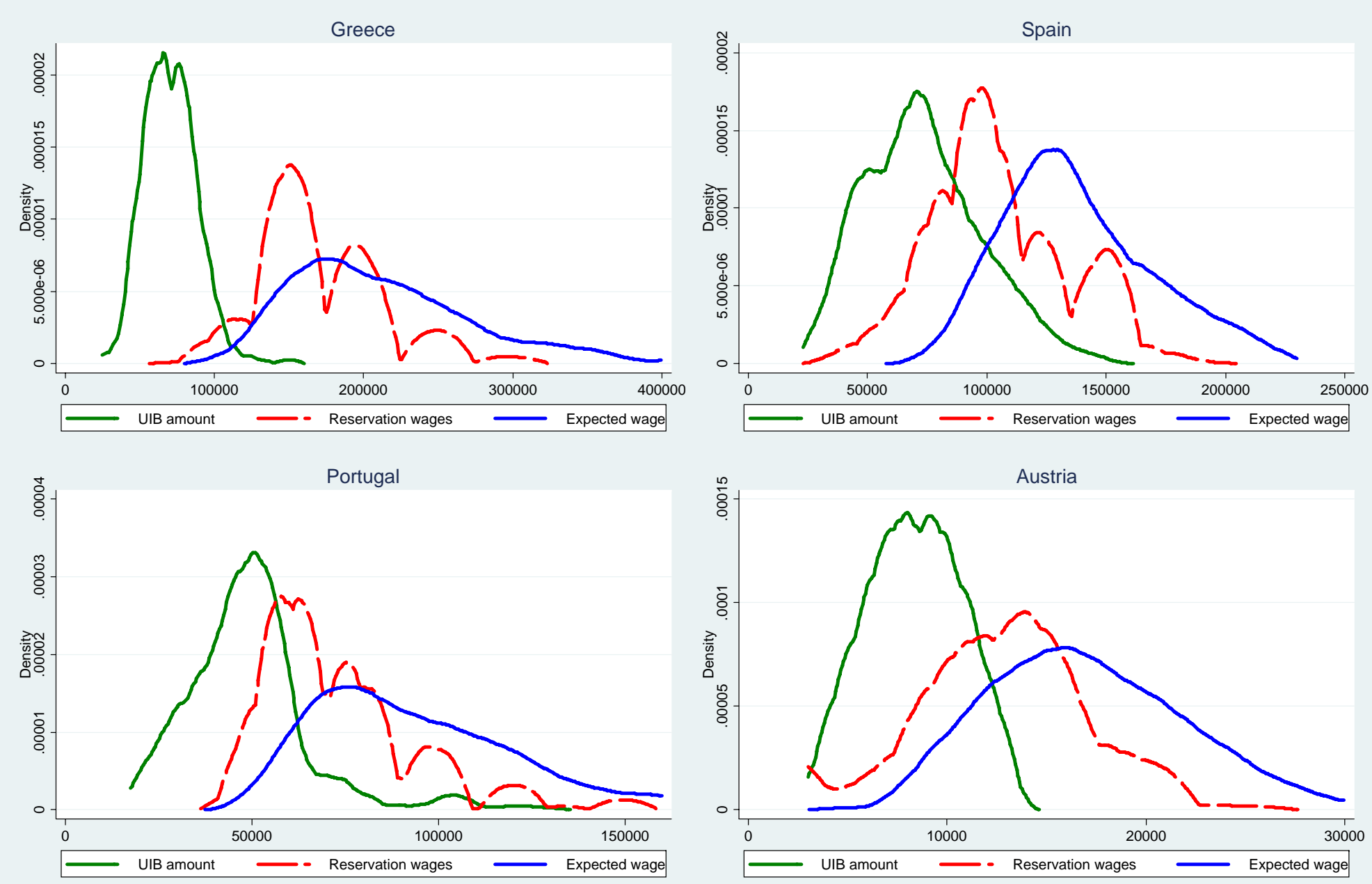

Source: European Community Household Panel, 1994-1999

Figure1(continued): Unemployment benefits, reservation wages and expected wages 
Appendix Table 1

AVER AGE BENFFIT AND OFFER PROBABILITY EL ASTICITIES OF RESERVATION WAGES AND UNEMPLOYMENT DURATION BY COLNTRY $1993-98$

\begin{tabular}{|c|c|c|c|c|c|c|c|c|c|c|c|c|}
\hline Country/Elasticity & Germany & Denmark & Netherlands & Belgium & France & U.K. & Ireland & Italy & Greece & Spain & Portugal & Austria \\
\hline \multicolumn{13}{|c|}{ (a) No sample restrictions } \\
\hline \multirow{2}{*}{$\eta_{\xi, \mathrm{b}}$} & 0.420 & 0.657 & 1.030 & 0.299 & 0.402 & 0.612 & 0.297 & 0.189 & 0.140 & 0.499 & 0.383 & 0.340 \\
\hline & $(0.024)$ & $(0.036)$ & $(0.144)$ & $(0.021)$ & $(0.012)$ & $(0.053)$ & $(0.015)$ & $(0.046)$ & $(0.007)$ & $(0.019)$ & $(0.017)$ & $(0.038)$ \\
\hline \multirow[t]{2}{*}{$\eta_{\xi, \lambda}$} & 0.134 & 0.008 & 0.100 & 0.115 & 0.151 & 0.229 & 0.173 & 0.128 & 0.163 & 0.095 & 0.123 & 0.296 \\
\hline & $(0.009)$ & $(0.018)$ & $(0.065)$ & $(0.008)$ & $(0.005)$ & (0.034) & $(0.005)$ & $(0.011)$ & $(0.005)$ & $(0.006)$ & $(0.004)$ & $(0.007)$ \\
\hline \multicolumn{13}{|l|}{ Pareto distribution } \\
\hline \multirow[t]{2}{*}{$\eta_{\theta, \mathrm{b}}$} & -1.395 & -2.295 & -2.111 & -1.241 & -1.272 & -1.220 & -0.920 & -0.922 & -0.714 & -1.791 & -1.772 & -1.342 \\
\hline & $(0.093)$ & $(0.120)$ & $(0.303)$ & $(0.085)$ & $(0.042)$ & $(0.097)$ & $(0.050)$ & $(0.215)$ & $(0.032)$ & $(0.067)$ & $(0.064)$ & $(0.190)$ \\
\hline \multirow[t]{2}{*}{$\eta_{\theta, \lambda}$} & 0.556 & 0.973 & 1.205 & 0.520 & 0.523 & 0.954 & 0.462 & 0.374 & 0.173 & 0.658 & 0.432 & 0.697 \\
\hline & $(0.031)$ & $(0.073)$ & $(0.146)$ & $(0.043)$ & $(0.018)$ & $(0.065)$ & $(0.016)$ & $(0.052)$ & $(0.028)$ & $(0.025)$ & $(0.020)$ & $(0.078)$ \\
\hline \multicolumn{13}{|c|}{ Exponential distribution } \\
\hline \multirow[t]{2}{*}{$\eta_{\theta, \mathrm{b}}$} & -0.942 & -2.097 & -1.605 & -0.936 & -0.835 & -0.358 & -0.753 & -0.718 & -0.547 & -1.421 & -1.470 & -1.092 \\
\hline & $(0.056)$ & $(0.080)$ & $(0.255)$ & $(0.048)$ & $(0.022)$ & $(0.012)$ & $(0.038)$ & (0.197) & $(0.015)$ & $(0.049)$ & $(0.060)$ & $(0.066)$ \\
\hline \multirow[t]{2}{*}{$\eta_{\theta, \lambda}$} & 0.554 & 0.658 & 0.942 & 0.410 & 0.549 & 0.635 & 0.476 & 0.320 & 0.306 & 0.592 & 0.506 & 0.607 \\
\hline & $(0.180)$ & $(0.024)$ & $(0.094)$ & $(0.015)$ & $(0.008)$ & $(0.018)$ & $(0.014)$ & $(0.036)$ & $(0.011)$ & $(0.014)$ & $(0.012)$ & $(0.054)$ \\
\hline $\mathrm{n}$ & 941 & 659 & 156 & 684 & 1675 & 398 & 260 & 193 & 283 & 1055 & 420 & 177 \\
\hline \multicolumn{13}{|c|}{ (b) Restriction: reservation wage > unemployment benefits } \\
\hline \multirow[t]{2}{*}{$\eta_{\xi, \mathrm{b}}$} & 0.296 & 0.366 & 0.464 & 0.214 & 0.292 & 0.237 & 0.263 & 0.226 & 0.136 & 0.349 & 0.342 & 0.311 \\
\hline & $(0.008)$ & $(0.010)$ & $(0.028)$ & $(0.008)$ & $(0.006)$ & $(0.013)$ & $(0.012)$ & $(0.017)$ & $(0.006)$ & $(0.008)$ & $(0.012)$ & $(0.014)$ \\
\hline \multirow[t]{2}{*}{$\eta_{\xi, \lambda}$} & 0.181 & 0.112 & 0.174 & 0.151 & 0.192 & 0.251 & 0.182 & 0.129 & 0.163 & 0.141 & 0.138 & 0.155 \\
\hline & $(0.003)$ & $(0.002)$ & $(0.011)$ & $(0.004)$ & $(0.002)$ & (0.005) & (0.004) & (0.005) & (0.006) & (0.002) & $(0.003)$ & $(0.005)$ \\
\hline \multicolumn{13}{|l|}{ Pareto distribution } \\
\hline \multirow[t]{2}{*}{$\eta_{\theta, \mathrm{b}}$} & -0.981 & -1.279 & -0.952 & -0.887 & -0.725 & -0.873 & -0.815 & -0.701 & -0.690 & -1.254 & -1.584 & -0.838 \\
\hline & $(0.025)$ & $(0.030)$ & $(0.050)$ & $(0.035)$ & $(0.016)$ & $(0.026)$ & $(0.041)$ & $(0.074)$ & (0.033) & (0.025) & $(0.050)$ & $(0.039)$ \\
\hline \multirow[t]{2}{*}{$\eta_{\theta, \lambda}$} & 0.398 & 0.610 & 0.443 & 0.374 & 0.392 & 0.399 & 0.434 & 0.372 & 0.174 & 0.493 & 0.361 & 0.581 \\
\hline & $(0.010)$ & $(0.008)$ & $(0.021)$ & $(0.013)$ & $(0.008)$ & $(0.011)$ & $(0.014)$ & $(0.025)$ & $(0.029)$ & $(0.008)$ & $(0.015)$ & $(0.013)$ \\
\hline \multicolumn{13}{|c|}{ Exponential distribution } \\
\hline \multirow[t]{2}{*}{$\eta_{\theta, \mathrm{b}}$} & -0.785 & -0.752 & -0.807 & -0.880 & -0.519 & -0.502 & -0.681 & -0.535 & -0.549 & -1.169 & -1.362 & -0.998 \\
\hline & (0.016) & $(0.051)$ & (0.094) & $(0.031)$ & (0.012) & $(0.010)$ & $(0.027)$ & $(0.076)$ & $(0.014)$ & $(0.025)$ & $(0.050)$ & $(0.044)$ \\
\hline \multirow[t]{2}{*}{$\eta_{\theta, \lambda}$} & 0.470 & 0.481 & 0.448 & 0.369 & 0.489 & 0.496 & 0.451 & 0.358 & 0.301 & 0.494 & 0.483 & 0.469 \\
\hline & $(0.008)$ & $(0.009)$ & $(0.023)$ & $(0.009)$ & $(0.005)$ & $(0.015)$ & $(0.014)$ & $(0.018)$ & $(0.012)$ & $(0.007)$ & $(0.010)$ & $(0.015)$ \\
\hline $\mathrm{n}$ & 835 & 590 & 107 & 630 & 1531 & 319 & 250 & 161 & 279 & 942 & 392 & 154 \\
\hline
\end{tabular}

Source

European Community Household Panel, 1994-99

Bootstrap standard deviations in parenthesis 
Appendix Table 2

AVERAGE BENEFIT AND OFFER PROBABILITY ELASTICITIES OF RESERVATION WAGES AND UNEMPLOYMENT DURATION BY COUNTRY, USING ACTUAL ACCEPTED WAGES, 1993-98

\begin{tabular}{|c|c|c|c|c|c|c|c|c|c|c|c|c|}
\hline Country/Elasticity & Germany & Denmark & Netherlands & Belgium & France & U.K. & Ireland & Italy & Greece & Spain & Portugal & Austria \\
\hline \multicolumn{13}{|c|}{ Restriction: reservation wage $>$ unemployment benefits and reservation wages $<$ accepted wages } \\
\hline \multirow[t]{2}{*}{$\eta_{\xi, \mathrm{b}}$} & 0.237 & 0.385 & 0.385 & 0.139 & 0.230 & 0.227 & 0.227 & 0.156 & 0.187 & 0.349 & 0.348 & 0.240 \\
\hline & $(0.019)$ & $(0.027)$ & $(0.078)$ & $(0.017)$ & $(0.023)$ & $(0.039)$ & $(0.032)$ & $(0.023)$ & $(0.026)$ & $(0.028)$ & $(0.045)$ & $(0.029)$ \\
\hline \multirow[t]{2}{*}{$\eta_{\xi, \lambda}$} & 0.109 & 0.079 & 0.087 & 0.109 & 0.103 & 0.198 & 0.131 & 0.120 & 0.182 & 0.113 & 0.095 & 0.126 \\
\hline & $(0.008)$ & $(0.005)$ & $(0.015)$ & $(0.009)$ & $(0.008)$ & $(0.020)$ & $(0.014)$ & $(0.015)$ & $(0.016)$ & $(0.007)$ & $(0.012)$ & $(0.013)$ \\
\hline \multicolumn{13}{|l|}{ Pareto distribution } \\
\hline \multirow[t]{2}{*}{$\eta_{\theta, \mathrm{b}}$} & -1.660 & -1.828 & -0.959 & -1.254 & -1.006 & -0.587 & -1.310 & -1.229 & -0.735 & -2.011 & -1.709 & -1.509 \\
\hline & $(0.090)$ & $(0.172)$ & $(0.350)$ & $(0.160)$ & $(0.275)$ & $(0.054)$ & $(0.163)$ & $(0.159)$ & $(0.043)$ & $(0.115)$ & $(0.281)$ & (0.189) \\
\hline \multirow[t]{2}{*}{$\eta_{\theta, \lambda}$} & 0.240 & 0.389 & 0.329 & 0.143 & 0.232 & 0.227 & 0.233 & 0.164 & 0.193 & 0.356 & 0.358 & 0.255 \\
\hline & $(0.018)$ & $(0.025)$ & $(0.068)$ & $(0.018)$ & $(0.023)$ & $(0.040)$ & $(0.032)$ & $(0.023)$ & $(0.023)$ & $(0.027)$ & $(0.038)$ & $(0.024)$ \\
\hline \multicolumn{13}{|c|}{ Exponential distribution } \\
\hline \multirow[t]{2}{*}{$\eta_{\theta, \mathrm{b}}$} & -1.328 & -1.631 & -1.363 & -1.013 & -1.082 & -0.362 & -1.051 & -0.874 & -0.630 & -1.736 & -1.353 & -1.505 \\
\hline & $(0.077)$ & $(0.170)$ & $(0.268)$ & $(0.116)$ & $(0.255)$ & $(0.028)$ & $(0.143)$ & $(0.135)$ & $(0.042)$ & $(0.095)$ & $(0.258)$ & $(0.184)$ \\
\hline \multirow[t]{2}{*}{$\eta_{\theta, \lambda}$} & 0.351 & 0.467 & 0.413 & 0.258 & 0.337 & 0.436 & 0.364 & 0.258 & 0.378 & 0.467 & 0.449 & 0.394 \\
\hline & $(0.022)$ & $(0.026)$ & $(0.089)$ & $(0.025)$ & $(0.027)$ & $(0.044)$ & $(0.034)$ & $(0.023)$ & $(0.042)$ & $(0.025)$ & $(0.039)$ & $(0.042)$ \\
\hline $\mathrm{n}$ & 129 & 115 & 24 & 60 & 120 & 59 & 45 & 27 & 32 & 153 & 50 & 25 \\
\hline
\end{tabular}

Source

European Community Household Panel, 1994-99

Note

Bootstrap standard deviations in parenthesis 